\title{
Paper platform for reflectometric determination of furfural and hydroxymethylfurfural in sugarcane liquor
}

\author{
Maria Izabel Milani, Eduardo Luiz Rossini, Karine Castoldi, Leonardo Pezza, Helena Redigolo Pezza * \\ Instituto de Química, Universidade Estadual Paulista “Julio de Mesquita Filho”, UNESP, R. Prof. Francisco Degni 55, P.O. Box 355, 14800-900 Araraquara, SP, Brazil
}

\section{A R T I C L E I N F O}

\section{Article history:}

Received 18 October 2016

Received in revised form 22 February 2017

Accepted 17 March 2017

Available online 31 March 2017

\section{Keywords:}

Sugarcane liquor

Furfural

Hydroxymethylfurfural

Diffuse reflectance spectroscopy

\begin{abstract}
A B S T R A C T
Cachaça is the popular name of sugarcane liquor obtained from fermented sugarcane mash broth. This is one of the most popular alcoholic beverages in Brazil and is gaining ground in the global market. One of the quality parameters established by Brazilian law is the sum of the concentrations of furfural and hydroxymethylfurfural, two compounds that give the beverage an unpleasant taste and have mutagenic potential. These two substances are usually determined by chromatographic techniques that employ toxic organic solvents that can be damaging to the health of the operator and to the environment. This paper describes the development of a new methodology to determine furfural and hydroxymethylfurfural in sugarcane liquor using a diffuse reflectance technique coupled with limited-area spot-testing on a paper platform. The new method presented LOQ values of $0.74 \mathrm{mg} \mathrm{L}^{-1}$ for furfural and $1.27 \mathrm{mg} \mathrm{L}^{-1}$ for hydroxymethylfurfural. Recoveries in the ranges $89.5-108 \%$ (furfural) and 96.3-106\% (hydroxymethylfurfural) indicated that there was no significant influence of the matrix in determination of the analytes. The method was applied using eleven sugarcane liquor samples from different locations in Brazil.
\end{abstract}

@ 2017 Elsevier B.V. All rights reserved.

\section{Introduction}

Sugarcane liquor is one of the most common alcoholic beverages in Brazil and is increasingly popular worldwide. It is also known by the names "sugarcane spirit" or "cachaça". In 2016, it was exported to over 40 countries, generating revenues of about US\$13.9 million [1].

This drink is obtained by distilling fermented sugarcane mash, and one of the quality parameters established by the Ministry of Agriculture, Livestock and Supply (MAPA) is the sum of the concentrations of furfural (FUR) and hydroxymethylfurfural (HMF), with a maximum limit of $5 \mathrm{mg}$ in $100 \mathrm{~mL}$ of anhydrous ethanol [2]. Unlike many contaminants, the formation of FUR and HMF not only occurs in the fermentation step; both substances can be produced in the broth if the harvesting is preceded by the burning of the sugarcane plants, which can lead to the generation of free sugars such as pentoses and hexoses in the broth. The degradation of the free sugars then results in the formation of FUR and HMF. These compounds are markers of heating processes in many products that contain sugars in their composition [3-7], and their presence in sugarcane liquor is undesirable because it gives the beverage unwanted features such as a penetrating and nauseating aroma [8]. Furthermore, due to the planarity of their structures (Fig. 1), FUR and HMF are potentially carcinogenic/mutagenic since they can interact with DNA molecules [9-15].

\footnotetext{
* Corresponding author.

E-mail address: hrpezza@iq.unesp.br (H.R. Pezza).
}

Several methodologies are available for the determination of FUR and HMF in many types of samples, mostly based on chromatography [16-20]. Although these techniques provide efficient separation and determination of the analytes, with low limits of detection, disadvantages are that they usually require the use of toxic organic solvents and that the instruments employed for the analyses are expensive and require specialist operators. The method involving electrophoretic separation [21] offers an analysis without organic solvent, but the instrumentation required has higher added cost, compared to the equipment needed in the analytical method proposed here, and also necessitates a specialized operator. The methodology with digital image detection [22] is an example of an analytical procedure that reduces the use of reagents and generates lower quantities of waste, compared to conventional procedures [2]. Nevertheless, the spot method [22] used only determines the furfural concentration, rather than the sum of HMF and FUR as required by legislation [2]. Therefore, for samples in which the amount of HMF and FUR exceeds the established limit, the FUR concentration could be below this limit (as in the case of sample G), generating a false negative. With the volume required for only one determination by the digital image procedure [22], it would be possible to perform around 40 analyses using the proposed method. In addition, the waste generated in the present method is solid and readily incinerable, while in the method proposed by Franco et al. [22], the residues produced have to be converted to harmless substances.

In most cases, analytical methodologies do not conform to the principles of Green Chemistry [23], which aims to minimize (or preferably 

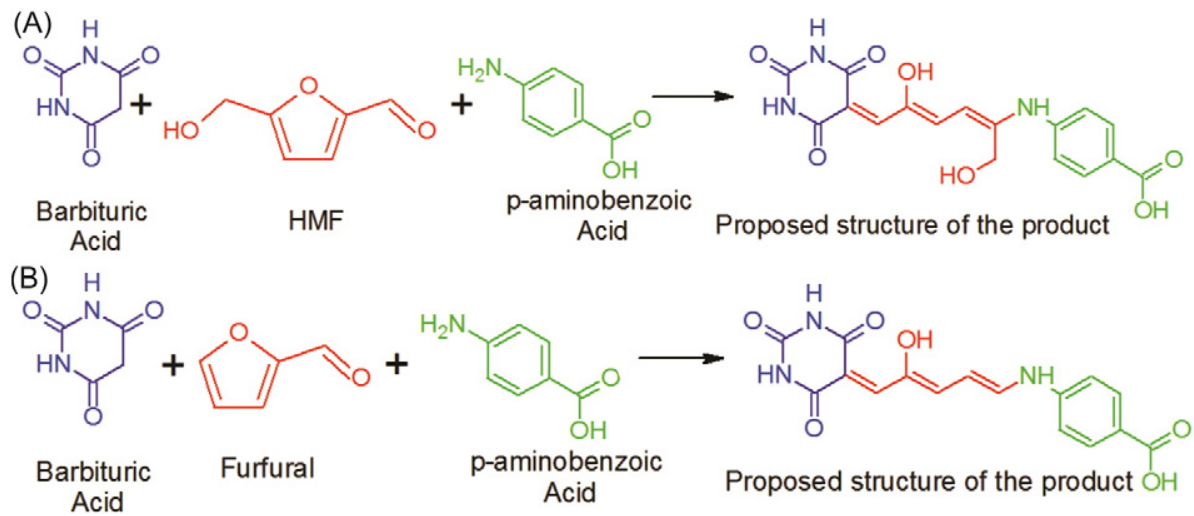

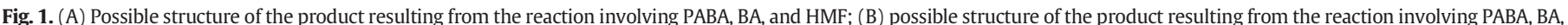
and FUR.

eliminate) the use of toxic organic solvents and develop simpler and less onerous methodologies. A good alternative method for the determination of FUR and HMF is diffuse reflectance spectroscopy, which is simpler than the chromatographic techniques usually used to analyze such compounds.

For many years, the use of reflectance spectroscopy was limited to paints and pigments, paper, textile areas, ceramics, dye-stuffs and printing inks to evaluate properties such as color, whiteness, gloss, covering power, and so on [24]. Recently with the development of optical devices such as integrating sphere assemblies, diffuse reflectance spectroscopy is rapidly gaining in acceptance in analytical chemistry. Application of diffuse reflectance spectroscopy especially associated to spot test has been reported in the literature indicating the potential of this technique for quantitative analysis [25-27].

In the present work, we describe a new spot test/diffuse reflectance spectroscopy method employing a paper platform delimited with hydrophobic barriers. The combination of diffuse reflectance spectroscopy and spot testing is eco-friendly because it uses minimal quantities of reagents and consequentially generates only minor amounts of waste, while the environmental and health risks are very low [23]. Filter paper is obtained from renewable sources and provides an excellent platform for spot tests due to its cellulose fiber composition and its white color, which provides a bright and high contrast background [24].

The use of hydrophobic barriers for impregnation of the filter paper platforms used in spot tests greatly improves the analyses by preventing the analyte and reagent solutions from eluting beyond the area defined by the barrier [28], hence increasing the concentration of the colored product and the magnitude of the analytical signal. The first report of the use hydrophobic barriers was in the work of Yagoda in 1937 [29], for determination of metal ions, and since then several papers have described the use of hydrophobic barriers in inexpensive and portable methodologies [30-32].

There are many ways to impregnate the hydrophobic barriers in the paper platform [31]. One method is wax printing, where a wax-based printer prints patterns of solid wax on the surface of the paper, followed by heating in an oven or on a hotplate [28]. When the wax ink is heated, it penetrates through the porous paper, creating the hydrophobic barriers that prevent the solution eluting beyond the delimited area.

\section{Experimental}

\subsection{Apparatus}

Diffuse reflectance measurements were made using a portable spectrophotometer (USB2000, Ocean Optics) controlled with OOIBase32 software (Ocean Optics). The spectrophotometer was coupled to an integrating sphere using an optical fiber. The comparative method employed a Shimadzu UFLC-20A HPLC system with a DAD detector [17].
A mass spectrometer (Thermo Scientific LCQ Fleet Ion Trap LC/MS ${ }^{\mathrm{n}}$ ) was used to determine the product structure.

\subsection{Materials, reagents, and solutions}

Whatman No. 1 qualitative filter paper was used as the solid support in the spot tests. All the reagents employed were analytical grade and were used without any prior purification. Analytical standards of furfural and hydroxymethylfurfural were obtained from J.T. Baker. Ultrapure water (18 $\mathrm{M} \Omega \mathrm{cm}$, Milli-Q system, Millipore) was used to prepare the solutions.

The reagent solutions were composed of a mixture of paminobenzoic acid (Henrifarma, Brazil), barbituric acid (Merck), and hydrochloric acid (Merck), at different concentrations for the determinations of HMF or FUR.

Stock standard solutions of $0.00550 \mathrm{~mol} \mathrm{~L}^{-1} \mathrm{HMF}$ and $0.00723 \mathrm{~mol} \mathrm{~L}^{-1}$ FUR were freshly prepared in aqueous $40 \%(\mathrm{v} / \mathrm{v})$ solutions of HPLC grade ethanol (J.T. Baker). Working solutions of FUR and HMF were prepared daily by appropriate dilutions of the stock solutions in aqueous $40 \%(\mathrm{v} / \mathrm{v})$ ethanol.

\subsection{Samples}

Eleven sugarcane liquor samples were used to evaluate the performance of the new method proposed here. The liquor samples were either sugared (B, C, D, F, I, and J) or non-sugared ( $, E, G, H$, and $K$ ), and were also classified as aged $(G$ and $H)$ or non-aged $(A, B, C, D, F, I$, $\mathrm{J}$, and $\mathrm{K}$ ). The samples originated from the states of São Paulo (A, B, C, D, E, F, G, and H), Paraná (I), Pernambuco (J), and Ceará (K).

\subsection{Procedure}

\subsubsection{Paper platform for spot tests}

CorelDRAW $\times 5$ was used to design hydrophobic barriers that were $15 \mathrm{~mm}$ in diameter and $0.75 \mathrm{~mm}$ in thickness. The design was printed onto Whatman No. 1 filter paper with wax toner (Genuine Xerox Solid Ink Black) using a wax printer (Xerox Phaser 8560), as described by Carrilho et al. [28]. After printing, the paper was heated for $120 \mathrm{~s}$ at $120{ }^{\circ} \mathrm{C}$ for formation of the hydrophobic barriers.

\subsubsection{Reagent solution}

The reagent solution, described in the work of Castoldi et al. [33], was based on the Winkler method for determination of HMF in honey samples [34]. This solution contained p-aminobenzoic acid (PABA), barbituric acid (BA), and hydrochloric acid $(\mathrm{HCl})$. The analytes were quantified separately using two different reagent solutions, both composed of PABA, BA, and $\mathrm{HCl}$, but at different concentrations, using a single spot test device for each analysis. The results were calculated as the sum of FUR and HMF. 


\subsubsection{Optimization of variables}

Since the sample medium consisted essentially of water and ethanol, it was necessary to determine the ethanol percentage that provided the best analytical response. The percentages tested were $35,40,45,50$, and $55 \%(\mathrm{v} / \mathrm{v})$ ethanol in water.

In preliminary tests, the effect of the $\mathrm{pH}$ of the reagent solution was studied using buffer solutions in order to improve the analytical response. Phosphate buffer was used for a neutral medium (pH 7.2). An acid medium ( $\mathrm{pH} 4.5$ ) was obtained using acetate buffer, and an alkaline medium ( $\mathrm{pH}$ 9.0) was obtained using ammonium buffer. The $\mathrm{pH}$ of deionized water ( $\mathrm{pH}$ 6.5) was also used.

A full $2^{3}$ factorial design was employed to identify the main parameters to be optimized, using Statistica 7 software. For both analytes, the parameters evaluated were the concentrations of PABA, BA, and $\mathrm{HCl}$.

The main parameters were used to construct response surfaces in order to find the optimal conditions for the two analytes. In the case of FUR, the parameters optimized were the PABA and $\mathrm{HCl}$ concentrations, while for $\mathrm{HMF}$, the parameters optimized were the $\mathrm{BA}$ and $\mathrm{HCl}$ concentrations. The response surfaces were constructed using Statistica 7 software.

\subsubsection{Comparative method}

The results obtained with the new methodology proposed here were validated by comparison with the results obtained using the methodology described by Alcázar et al. [17]. The chromatographic separations were performed at $35^{\circ} \mathrm{C}$ on a C- 18 column $(250 \times 4.6 \mathrm{~mm}, 5 \mu \mathrm{m}$ particle size), with isocratic elution using a mobile phase consisting of a mixture of acetonitrile (ACN) and an acid solution (acetic and phosphoric acids, $18: 82$ ), at a flow rate of $1.2 \mathrm{~mL} \mathrm{~min}{ }^{-1}$. The detection wavelength was $280 \mathrm{~nm}$.

\subsubsection{Products structure}

In order to confirm the products formed from the reaction involving PABA, BA, and FUR, a solution containing the analyte and reagents was analyzed using mass spectrometry in full scan negative mode. The operating conditions were a capillary voltage (ESI) of $5 \mathrm{kV}, \mathrm{N}_{2}$ flow rate of 8 (arbitrary units), transfer capillary temperature of $275^{\circ} \mathrm{C}$, transfer capillary voltage of $11 \mathrm{~V}$, and sample solution flow rate of $5 \mu \mathrm{L} \mathrm{min}{ }^{-1}$.

\section{Results and discussion}

\subsection{Preliminary tests}

The reagents selected for the colorimetric determination of FUR and HMF were PABA and BA, based on earlier work by our research group [33]. In this reaction, there is cleavage of the furanic ring, forming a product that absorbs radiation in the visible region, as represented in Fig. 1.

It can be seen from Fig. 2 that there is no spectral interference between the products. Fig. 2A shows a representation of both products using the specific reagent for furfural determination; the blue product has an absorption maximum at $616 \mathrm{~nm}$ (red line), while the hydroxymethylfurfural product (which would have a yellow coloration, black line) shows no analytical signal at this wavelength. The same applies using the specific reagent for HMF determination (Fig. 2B), in which is used the specific reagent for HMF determination; the characteristic yellow product presents an absorption maximum at $420 \mathrm{~nm}$ (black line), but when the HMF reagent for FUR determination is used, the product does not present any absorption (red line). Therefore, the use of a specific reagent for each analyte enables the determination of each of them without any interference from the other.

Evaluation was made of the influence of the order of addition of the reagent and analyte. It was found that the analytical response was greater and the color of the spot was more homogeneous when the reagent solution was added first, followed by the analyte solution. In the spot test, $15 \mu \mathrm{L}$ amounts of each reagent and analyte solutions were applied to the center of the delimited area.

An increase of approximately $30 \%$ in the signal was achieved when the spot area was delimited by the hydrophobic barriers, compared to an absence of barriers, due to the confinement of the solution within a limited space, bounded by the hydrophobic barriers. When the area was delimited, the standard deviations were smaller and the colors were sharper and more uniform.

\subsection{Optimization of experimental conditions}

The results of the tests showed that the percentage of ethanol did not significantly influence determination of the analytes. A percentage of $40 \%(\mathrm{v} / \mathrm{v})$ was therefore selected, because the most of the samples had alcohol contents of $38-39 \%$.

The tests to evaluate the influence of the $\mathrm{pH}$ of the reagent solution showed that an acid pH provided better responses for both analytes. However, after performing the experimental design, it was found that lower $\mathrm{pH}$ values were required, so a standardized $\mathrm{HCl}$ solution was used in subsequent analyses. A low $\mathrm{pH}$ was necessary to promote cleavage of the furanic ring, resulting in formation of the colored product.

The results obtained using the full factorial design (Table S1) showed that assay \#6 (maximum value of PABA, minimum values of BA and $\mathrm{HCl}$ ) presented better analytical responses for both analytes. The Pareto chart for FUR (Fig. S1A) showed that the PABA and $\mathrm{HCl}$ concentrations had the greatest influence on the measurement, with higher amounts of these two compounds resulting in a better analytical response. For HMF determination, the parameters that had the greatest influence

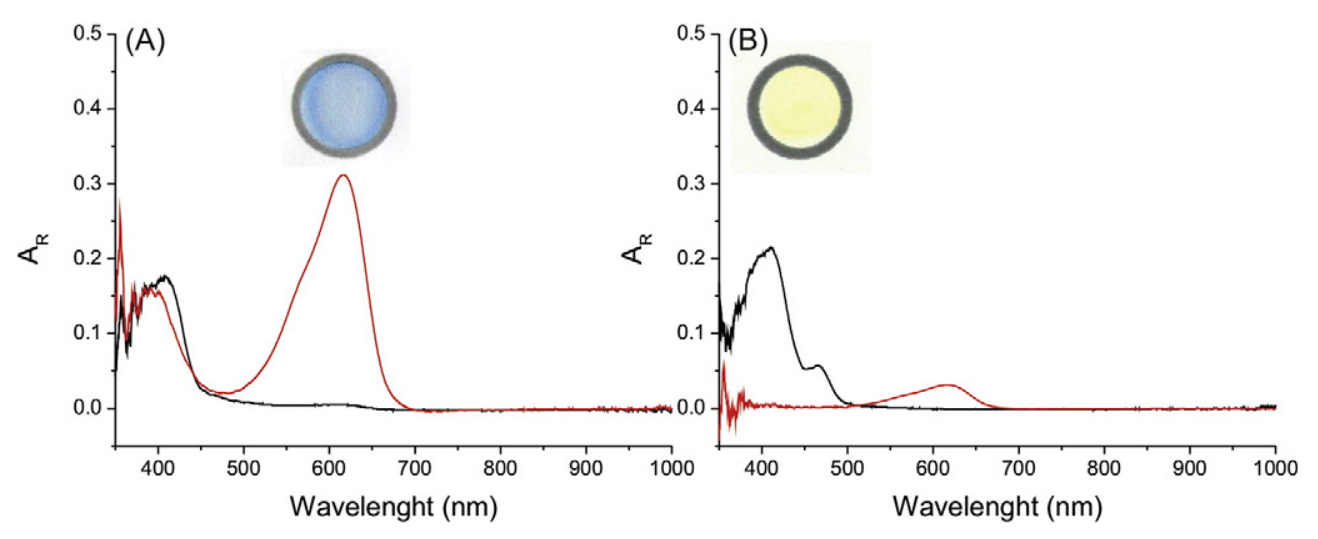

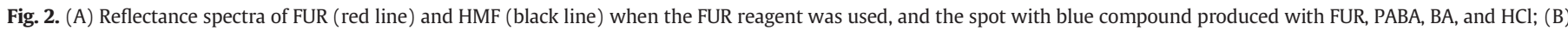
reflectance spectra of FUR (red line) and HMF (black line) when the HMF reagent was used, and the spot with yellow compound produced with HMF, PABA, BA, and HCl. 
were $\mathrm{HCl}$ and $\mathrm{BA}$, with higher amounts of $\mathrm{HCl}$ and lower amounts of $\mathrm{BA}$ resulting in a higher signal (Fig. S1B). It should be noted that PABA and $\mathrm{BA}$ must be present in the reactions used to determine the analytes, because if either of these reagents was absent, there was no formation of the characteristic colored products.

After determination of the most significant parameters for each analyte, individual response surfaces were constructed for the FUR and HMF reactions, with the aim of identifying the optimal experimental conditions and maximizing the analytical response. In the case of the FUR response surface, the parameters evaluated were the PABA and $\mathrm{HCl}$ concentrations, while for the HMF response surface, the concentrations of $\mathrm{HCl}$ and $\mathrm{BA}$ were evaluated. Table $\mathrm{S} 2$ provides the conditions of the response surfaces, together with the results obtained in each assay.

Fig. 3 illustrates the response surface graph for HMF, obtained from the fitting of the experimental data described in Table S2. The quadratic regression model describing the response surface graph is given by the following equation:

$$
\begin{aligned}
\mathrm{A}_{\mathrm{R}}= & 0.141+0.119[\mathrm{HCl}]-0.439[\mathrm{HCl}]^{2}+20.418[\mathrm{BA}]-667.926[\mathrm{BA}]^{2} \\
& +6.500[\mathrm{HCl}][\mathrm{BA}]
\end{aligned}
$$

The HMF response surface (Fig. 3 ) showed a maximum point that identified the experimental conditions at which the maximum analytical response was achieved. The optimum concentrations of $\mathrm{BA}$ and $\mathrm{HCl}$ were 0.017 and $0.27 \mathrm{~mol} \mathrm{~L}^{-1}$, respectively. Since the PABA concentration had only a minor influence on the HMF determination, the value that gave the best response in the factorial design tests was chosen (0.011 $\left.\mathrm{mol} \mathrm{L}^{-1}\right)$.

Fig. 4 shows the response surface for the FUR reaction. The quadratic regression model is given by:

$$
\begin{aligned}
\mathrm{A}_{\mathrm{R}}= & 0.005+0.625[\mathrm{HCl}]-89.083[\mathrm{HCl}]^{\complement}+6.511[\mathrm{PABA}]-45.889[\mathrm{PABA}]^{\mathrm{f}} \\
& +47.222[\mathrm{HCl}][\mathrm{PABA}]
\end{aligned}
$$

It can be seen that no maximum point corresponding to the optimal analysis conditions was achieved. Analysis of the response surface

\section{Fitted Surface; Variable: $A_{R}$ \\ 2 factors, 1 Blocks, 13 Runs; MS Residual=,0002449 DV: $A_{R}$}

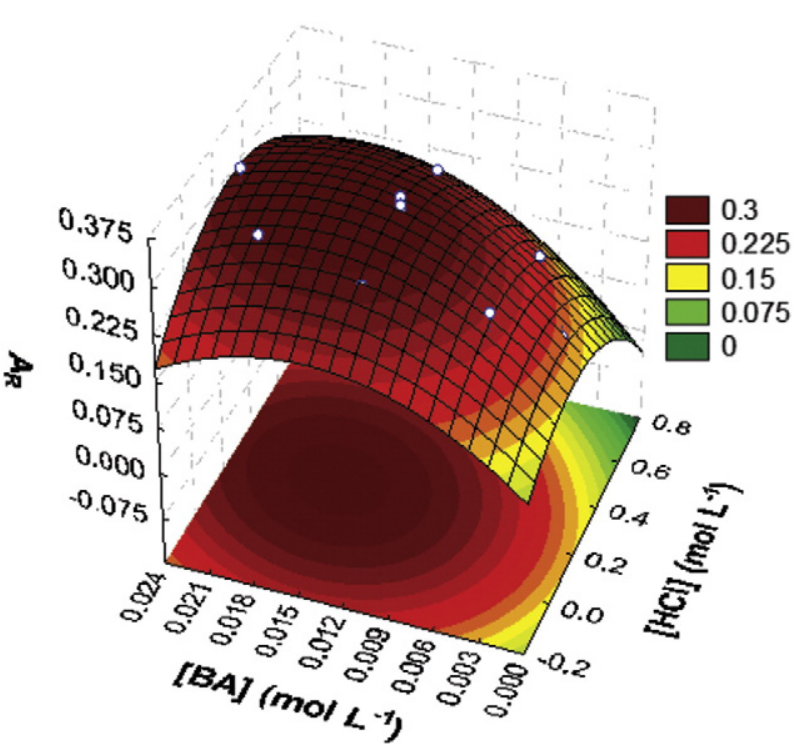

Fig. 3. Response surface for $H M F$ determination, with $A_{R}$ plotted as a function of the BA and $\mathrm{HCl}$ concentrations.

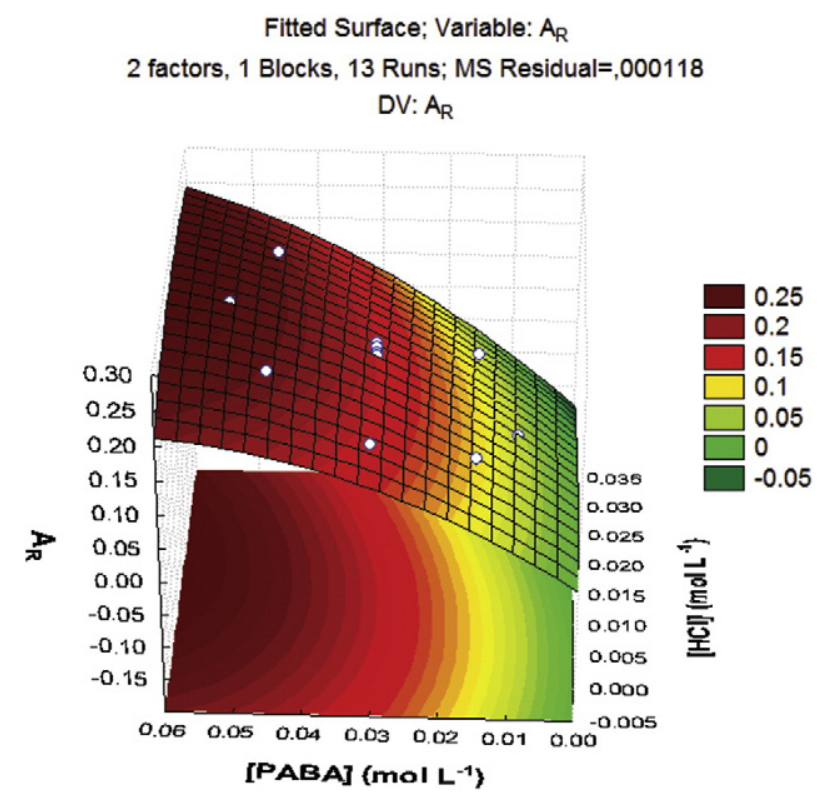

Fig. 4. Response surface for FUR determination, with $A_{R}$ plotted as a function of the PABA and $\mathrm{HCl}$ concentrations.

suggested that this was due to the need to increase the PABA concentration. However, this was not possible, since there was a limit to the solubility of PABA in the reagent solution. Hence, the maximum possible amount of PABA was used $\left(0.054 \mathrm{~mol} \mathrm{~L}^{-1}\right)$. In the case of the $\mathrm{HCl}$ concentration, the optimum value $\left(0.015 \mathrm{~mol} \mathrm{~L}^{-1}\right)$ was achieved, as can be seen in Fig. 4. For the BA concentration, the value used was $0.017 \mathrm{~mol} \mathrm{~L}^{-1}$, which has been found to provide the best analytical response in previous studies. Optical stability tests were performed in order to determine the times during which the reaction products remained stable under ambient conditions, after the spot test substrates had dried. Both products were found to be stable from 15 to $120 \mathrm{~min}$ after the reactions.

\subsection{Figures of merit}

After optimization of the experimental conditions, analytical curves were constructed for both analytes. For FUR, the linear range used was from $8.69 \times 10^{-6} \mathrm{~mol} \mathrm{~L}^{-1}$ to $4.17 \times 10^{-4} \mathrm{~mol} \mathrm{~L}^{-1}$, while for HMF, the linear range used was from $1.10 \times 10^{-5} \mathrm{~mol} \mathrm{~L}^{-1}$ to $7.91 \times 10^{-4} \mathrm{~mol} \mathrm{~L}^{-1}$. Linear relationships were found between the analytical responses $\left(A_{R}\right)$ and the square roots of the analyte concentrations $\left(C^{1 / 2}\right)$. The linear regression equation for HMF was $A_{R}=$ $15.822\left(C_{H M F}\right)^{1 / 2}-0.0263$, with correlation coefficient $(R)$ equal to 0.998. For FUR, the equation was $A_{R}=27.117\left(C_{F U R}\right)^{1 / 2}-0.027$, with $\mathrm{R}=0.997$. As Ghauch and co-workers pointed out, the analytical response does not necessarily show a direct linear relationship with the analyte concentration; the relation between these two parameters may be mathematically described by many types of plots, for example $A_{R} v s \log C$ and $A_{R} v s C^{1 / 3}[35,25]$. In the present case, a linear relation between analytical response and analyte concentration was obtained using $A_{R} v s C^{1 / 2}$, as also found by Rossini et al. [27].

The repeatability of the proposed method was evaluated using the relative standard deviations (\%RSD) obtained for intra-day and interday tests [36] at two different concentrations. For a $5 \mathrm{mg} \mathrm{L}^{-1}$ solution of FUR, the values obtained were 3.4\% (intra-day) and 3.7\% (interday), while for a $40 \mathrm{mg} \mathrm{L}^{-1}$ solution, the values found were $1.1 \%$ and $1.8 \%$, respectively. For a $5 \mathrm{mg} \mathrm{L}^{-1} \mathrm{HMF}$ solution, the intra-day and inter-day repeatability values were $3.2 \%$ and $5.5 \%$, respectively, while for a $20 \mathrm{mg} \mathrm{L}^{-1} \mathrm{HMF}$ solution, the values were $2.4 \%$ and $2.6 \%$, respectively. These values were considered acceptable [37] and demonstrated 
that the method proposed here is repeatable and can be used for FUR and HMF analyses.

The LOD and LOQ values were determined according to the IUPAC recommendations [38]: $\mathrm{LOD}=3^{*} \mathrm{\sigma} / \mathrm{S}$ and $\mathrm{LOQ}=10^{*} \mathrm{\sigma} / \mathrm{S}$, where $\sigma$ is the standard deviation of measurements of the blank $(n=10)$ and $\mathrm{S}$ is the slope of the linear range. For FUR, the values found were $6.93 \times 10^{-7} \mathrm{~mol} \mathrm{~L}^{-1}\left(0.067 \mathrm{mg} \mathrm{L}^{-1}\right)$ and $7.70 \times 10^{-6} \mathrm{~mol} \mathrm{~L}^{-1}$ ( $\left.0.740 \mathrm{mg} \mathrm{L}^{-1}\right)$, respectively. For HMF, the values found were $9.03 \times 10^{-6} \mathrm{~mol} \mathrm{~L}^{-1}\left(0.114 \mathrm{mg} \mathrm{L}^{-1}\right)$ and $1.00 \times 10^{-5} \mathrm{~mol} \mathrm{~L}^{-1}$ (1.27 $\left.\mathrm{mg} \mathrm{L}^{-1}\right)$, respectively. The LOD and LOQ values were therefore appropriate for the determination of FUR and HMF by the proposed method.

\subsection{Recovery tests}

In order to evaluate the influence of the matrix, recovery tests were performed using two types of samples: a non-sugared aged sample and a sugared sample that had not been aged. Both types of samples were fortified with FUR and HMF at levels ranging from 7.60 to $35.0 \mathrm{mg} \mathrm{L}^{-1}$ for FUR and from 13.1 to $45.9 \mathrm{mg} \mathrm{L}^{-1}$ for HMF. For the first type of sample, the recovery values were between $93.0 \%$ and $108 \%$ for FUR and between $96.2 \%$ and $102 \%$ for HMF. For the second type of sample, the recoveries were between $89.5 \%$ and $106 \%$ for FUR and between $100 \%$ and $106 \%$ for HMF. These results showed that none of the sample matrices had any significant influence on the FUR and HMF determinations. Besides, this test demonstrated that compounds commonly present in sugarcane liquid samples, as sucrose, higher alcohols, ethyl carbamate, acetic acid, ethyl acetate and acetaldehyde, presented no interferences in the proposed method, demonstrating the selectivity of the reaction for HMF and FUR determination.

\subsection{Determination of FUR and HMF in sugarcane liquor}

The proposed method was applied using eleven samples (described in Section 2.3) and the results obtained were compared with those obtained by a method already described in the literature. We chose to use the chromatographic technique described by Alcázar et al. [17], reproducing the experimental conditions in our laboratory using a similar chromatographic system and column, as described in Section 2.4.4.

The concentrations of FUR and HMF were determined separately and then summed to obtain the value required by legislation [2]. In order to achieve a better comparison of the methods, the results were compared analyte by analyte. In other words, the furfural results obtained for each method were compared to each other, as were the results obtained in the hydroxymethylfurfural analyses. Table 1 shows the results obtained for the two analytes and the different methods. For both FUR and HMF, the two methodologies gave similar values; with the Student's $t$-test indicating that there were no significant differences between the techniques (the calculated t-values were lower than the tabulated t-values).

In the same Table 1 there is the sums of the FUR and HMF values (as required by Brazilian law) for the sugarcane liquors. Only one sample (G) showed a concentration higher than the permitted value, which was probably because caramel dye had been added in order to simulate an aged beverage. These results were indicative of the excellent quality of the Brazilian sugarcane liquors, which complied with the requirements for export and internal consumption.

A comparison of the proposed method and other methods found in the literature is provided in Table 2. The linear ranges and LOQ values of the new technique were suitable for the intended purpose and were superior to some of the earlier methods. The new method does not use toxic organic solvents (which are required in chromatographic analyses), the sample can be analyzed directly without pretreatment or dilution, and the equipment is low cost. It can be seen from Table 2 that for many types of samples, there is a lack of simultaneous determinations of these two compounds using portable and easily implemented methodologies. For example, the official quality parameter is the sum of the concentrations of furfural and hydroxymethylfurfural, but the image-based colorimetric method was only used to analyze furfural in sugarcane liquor. In addition, the proposed method shows adequate sensibility for the determination of FUR and HMF in sugarcane liquid samples according to Brazilian law [2].

\subsection{Determination of product structure}

The structure of the colored product formed in the reaction involving PABA, BA, and HMF was described by Castoldi et al. [33] and is illustrated in Fig. 1A. In the present work, the solution of reagents and furfural was analyzed by mass spectrometry, using the conditions described in Section 2.4.5. Fig. S2 presents the fragmentograms of the products obtained in the reaction involving PABA, BA, and FUR. The structure of the product (Fig. 1B) is based on the work of Winkler [34], with PABA as a substance analogous to aniline.

The suggested product of the FUR reaction (Fig. 1B) has a molecular mass of approximately $343 \mathrm{~g} \mathrm{~mol}^{-1}$. The spectrum acquired in negative mode showed a base peak at $m / z 342.00$, corresponding to the molecular ion (M-1), in agreement with the proposed structure. The main peaks at $\mathrm{m} / \mathrm{z} 299$ and 256 represented the losses of CONH and $2(\mathrm{CONH})$, respectively. The other peaks in the spectrum were not relevant for determining the product structure. The fragmentation

Table 1

Results obtained using the proposed and comparative methods in sugarcane liquor samples.

\begin{tabular}{|c|c|c|c|c|c|c|c|c|}
\hline \multirow[t]{2}{*}{ Sample } & \multicolumn{3}{|l|}{ Hydroxymethylfurfural } & \multicolumn{3}{|l|}{ Furfural } & \multicolumn{2}{|l|}{ Sum of FUR and HMF } \\
\hline & Comparative method [27] & Proposed method ${ }^{\mathrm{a}}$ & $t$-test ${ }^{\mathrm{b}}$ & Comparative method [27] & Proposed method ${ }^{\mathrm{a}}$ & $t$-test ${ }^{\mathrm{b}}$ & Comparative method [27] ${ }^{\mathrm{a}}$ & Proposed method $^{\mathrm{a}}$ \\
\hline$A$ & $<\mathrm{LOQ}^{\mathrm{c}}$ & $<\mathrm{LOQ}^{\mathrm{d}}$ & - & $0.139 \pm 0.000$ & $0.137 \pm 0.009$ & 1.102 & $0.139 \pm 0.000$ & $0.137 \pm 0.009$ \\
\hline B & $0.215 \pm 0.000$ & $0.18 \pm 0.02$ & 3.566 & $<\mathrm{LOQ}^{\mathrm{e}}$ & $<\mathrm{LOQ}^{\mathrm{f}}$ & - & $0.215 \pm 0.000$ & $0.18 \pm 0.02$ \\
\hline $\mathrm{C}$ & $0.275 \pm 0.001$ & $0.28 \pm 0.04$ & 0.282 & $<$ LOQ & $<\mathrm{LOQ}$ & - & $0.275 \pm 0.001$ & $0.28 \pm 0.04$ \\
\hline $\mathrm{D}$ & $<\mathrm{LOQ}$ & $<$ LOQ & - & $<\mathrm{LOQ}$ & $<\mathrm{LOQ}$ & - & $<$ LOQ & $<$ LOQ \\
\hline $\mathrm{E}$ & $<$ LOQ & $<\mathrm{LOQ}$ & - & $<\mathrm{LOQ}$ & $<\mathrm{LOQ}$ & - & $<\mathrm{LOQ}$ & $<$ LOQ \\
\hline $\mathrm{F}$ & $0.178 \pm 0.000$ & $0.20 \pm 0.02$ & 1.304 & $0.06 \pm 0.02$ & $<\mathrm{LOQ}$ & - & $0.235 \pm 0.000$ & $0.20 \pm 0.02$ \\
\hline G & $6.77 \pm 0.02$ & $6.7 \pm 0.1$ & 0.926 & $0.12 \pm 0.03$ & $0.130 \pm 0.009$ & 0.329 & $6.889 \pm 0.003$ & $6.8 \pm 0.1$ \\
\hline $\mathrm{H}$ & $0.062 \pm 0.000$ & $<\mathrm{LOQ}$ & - & $0.386 \pm 0.003$ & $0.35 \pm 0.02$ & 2.937 & $0.449 \pm 0.003$ & $0.35 \pm 0.02$ \\
\hline I & $0.362 \pm 0.001$ & $0.32 \pm 0.04$ & 2.029 & $<\mathrm{LOQ}$ & $<\mathrm{LOQ}$ & - & $0.362 \pm 0.001$ & $0.32 \pm 0.04$ \\
\hline $\mathrm{J}$ & $<\mathrm{LOQ}$ & $<\mathrm{LOQ}$ & - & $<\mathrm{LOQ}$ & $<\mathrm{LOQ}$ & - & $<\mathrm{LOQ}$ & $<\mathrm{LOQ}$ \\
\hline $\mathrm{K}$ & $<$ LOQ & $<$ LOQ & - & $<$ LOQ & $<$ LOQ & - & $<\mathrm{LOQ}$ & $<$ LOQ \\
\hline
\end{tabular}

a Results expressed in $\mathrm{mg} / 100 \mathrm{~mL}$ anhydrous ethanol.

b Tabulated value of 4.303 (95\% confidence interval and 2 degrees of freedom).

c $\operatorname{LOQ}(\mathrm{FUR})=0.74 \mathrm{mg} \mathrm{L}^{-1}$.

d $\mathrm{LOQ}$ (FUR) $=0.1 \mathrm{mg} \mathrm{L}^{-1}$.

e $\mathrm{LOQ}(\mathrm{HMF})=0.1 \mathrm{mg} \mathrm{L}^{-1}$.

${ }^{\mathrm{f}} \mathrm{LOQ}(\mathrm{HMF})=1.27 \mathrm{mg} \mathrm{L}^{-1}$. 
Table 2

Methodologies for the determination of furfural and/or hydroxymethylfurfural in different types of samples.

\begin{tabular}{|c|c|c|c|c|c|c|c|}
\hline \multirow[t]{2}{*}{ Matrix } & \multirow[t]{2}{*}{ Technique } & \multirow[t]{2}{*}{ Comments } & \multicolumn{2}{|c|}{ Linear range $\left(\mathrm{mg} \mathrm{L}^{-1}\right)$} & \multicolumn{2}{|l|}{ LOQ $\left(\mathrm{mg} \mathrm{L}^{-1}\right)$} & \multirow[t]{2}{*}{ Ref. } \\
\hline & & & FUR & HMF & FUR & HMF & \\
\hline Beer & $\begin{array}{l}\text { HPLC with UV } \\
\text { and RI } \\
\text { detection }\end{array}$ & Mobile phase containing $\mathrm{H}_{2} \mathrm{SO}_{4}$ and $\mathrm{ACN}$ & Not analyzed & $(1-128) \times 10^{3}$ & Not analyzed & 0.036 & {$[16]$} \\
\hline Alcoholic beverages & $\begin{array}{l}\text { HPLC with UV } \\
\text { detection }\end{array}$ & ACN used in mobile phase and for sample dilution & Not cited & Not cited & $15.9 \times 10^{-6}$ & $28 \times 10^{-6}$ & {$[17]$} \\
\hline Cookies & $\begin{array}{l}\text { HPLC with UV } \\
\text { detection }\end{array}$ & Extraction process using trichloroacetic acid & Not analyzed & $0.02-20.2$ & Not analyzed & 0.02 & {$[18]$} \\
\hline Honey and biomass & HPAE-PAD & $\begin{array}{l}\text { Online generation of } \mathrm{KOH} . \mathrm{Ag} / \mathrm{AgCl} \text { reference } \\
\text { electrode }\end{array}$ & Not analyzed & $0.1-50 \times 10^{-3}$ & Not analyzed & $0.10 \times 10^{-3}$ & {$[19]$} \\
\hline Sugarcane bagasse & $\begin{array}{l}\text { HPLC with } \\
\text { electrochemical } \\
\text { detection }\end{array}$ & $\begin{array}{l}\text { Development of modified electrode with nickel } \\
\text { nanoparticles. Mobile phase containing ACN }\end{array}$ & $\begin{array}{l}8.32 \times 10^{-6} \\
-1.04 \times 10^{-4}\end{array}$ & $\begin{array}{l}6.34 \times 10^{-6} \\
-7.93 \times 10^{-5}\end{array}$ & $1.35 \times 10^{-5}$ & $1.11 \times 10^{-5}$ & {$[20]$} \\
\hline Honey & $\begin{array}{l}\text { Capillary } \\
\text { electrophoresis }\end{array}$ & $\begin{array}{l}\text { Caffeine used as an internal standard and sodium } \\
\text { tetraborate }+ \text { sodium dodecyl sulfate as an } \\
\text { electrolyte solution }\end{array}$ & Not analyzed & $10-80$ & Not analyzed & 0.31 & {$[21]$} \\
\hline Distilled beverages & Colorimetric & $\begin{array}{l}\text { Based on the reaction of furfural with the anilinium } \\
\text { ion, forming furfulidenaneline, which was quantified } \\
\text { colorimetrically at } 520 \mathrm{~nm}\end{array}$ & Not cited & Not cited & Not cited & Not cited & {$[2]$} \\
\hline Sugarcane liquor & Digital image & $\begin{array}{l}\text { Digital image detection with a smartphone to } \\
\text { determine only furfural in sugarcane liquors. } 600 \mu \mathrm{L} \\
\text { of reagent solution used in each spot }\end{array}$ & $6.68-40.0$ & Not analyzed & 4.6 & Not analyzed & {$[22]$} \\
\hline Sugarcane liquor & $\begin{array}{l}\text { Diffuse } \\
\text { reflectance }\end{array}$ & $\begin{array}{l}\text { Required no sample treatment. Used no toxic organic } \\
\text { solvents and } 15 \mu \mathrm{L} \text { of reagent solution }\end{array}$ & $0.84-40.1$ & $1.39-99.8$ & 0.74 & 1.27 & This work \\
\hline
\end{tabular}

HPLC: High Performance Liquid Chromatography.

RI: Refractive index.

UV: Ultraviolet.

HPAE: High-Performance Anion-Exchange Chromatography.

PAD: Pulsed Amperometric Detection.

ACN: Acetonitrile.

mechanism is not described here, because this was not one of the main objectives of the present work.

\section{Conclusions}

The new method is effective for the determination of furfural and hydroxymethylfurfural in sugarcane liquors using a delimited spot test with diffuse reflectance detection. The hydrophobic barriers used in this work significantly increased the sensitivity of the method, without any need for heating or the use of toxic organic solvents. In comparison against a chromatographic technique, the proposed methodology was found to be precise, accurate, safer, cheaper, and more environmentally friendly, generating less waste material than the comparative method. The vast majority of the sugarcane liquor samples analyzed showed values for the sum of FUR and HMF that were below the limit imposed by law. The structures of the products formed in the reactions involving p-aminobenzoic acid, barbituric acid, and the analytes were confirmed by mass spectrometry analysis.

\section{Acknowledgments}

We would like to thank the National Council for Scientific and Technological Development (CNPq) and the Research Support Foundation of São Paulo State (FAPESP, process no 2015/21733-1) for financial support, and the Institute of Chemistry of UNESP (Araraquara, São Paulo, Brazil) for the use of facilities.

\section{Appendix A. Supplementary data}

Supplementary data to this article can be found online at http://dx. doi.org/10.1016/j.microc.2017.03.046.

\section{References}

[1] Ministry of Agriculture Livestock and Food Supply, Exportation numbers of sugarcane liquor(n.d.) http://agrostat2.agricultura.gov.br/QvAjaxZfc/QvsViewClient. aspx public $=$ only\&size $=$ long\&host $=$ QVS\%40masrv1005\&name $=$ Temp $/$ bc0f8fb288594bc09932c9d7f64dae3e.html 2017 (accessed October 1, 2017).

[2] Ministry of Agriculture Livestock and Food Supply, Regulamento técnico para fixação dos padrões de identidade e qualidade para aguardente de cana e para cachaça, http://www.agricultura.gov.br/assuntos/laboratorios/metodos/arquivosmetodos-da-area-bev-iqa/destilados-22-furfural.pdf 2005.

[3] M. Mesias-Garicia, E. Guerra-Hernández, B. Garcia-Villanova, Determination of furan precursors and some thermal damage markers in baby foods: ascorbic acid, dehydroascorbic acid, hydroxymethylfurfural and furfural, J. Agric. Food Chem. 58 (2010).

[4] Z. Ciesarová, K. Kukurová, A. Bednáriková, F.J. Morales, Effect of heat treatment and dough formulation on the formation of Maillard reaction products in fine bakery products - benefits and weak points, J. Food Nutr. Res. 48 (2009) 20-30.

[5] A. Rajchl, H. Čižková, M. Voldřich, M. Jirušková, R. Ševčík, Evaluation of shelf life and heat treatment of tomato products, Czech J. Food Sci. 27 (2009) 130-133.

[6] S. Cattaneo, A. Hidalgo, F. Masotti, M. Stuknyte, A. Brandolini, I. De Noni, Heat damage and in vitro starch digestibility of puffed wheat kernels, Food Chem. 188 (2015) 286-293.

[7] F.W.B. de Aquino, S. Rodrigues, R.F. do Nascimento, A.R.S. Casimiro, Simultaneous determination of aging markers in sugar cane spirits, Food Chem. 98 (2006) 569-574.

[8] L.M. de Souza, K.S. Ferreira, L.C. Passoni, A.B. Bevitori, K.V. Melo, A.R. Viana, Teores de compostos orgânicos em cachaças produzidas na região norte fluminense - Rio de Janeiro, Quim Nova 32 (2009) 2304-2309.

[9] Q.A. Khan, F.A. Shamsi, S.M. Hadi, Mutagenicity of furfural in plasmid DNA, Cancer Lett. 89 (1995) 95-99.

[10] E. Capuano, V. Fogliano, Acrylamide and 5-hydroxymethylfurfural (HMF): a review on metabolism, toxicity, occurrence in food and mitigation strategies, LWT Food Sci. Technol. 44 (2011) 793-810.

[11] K. Abraham, G. Rainer, K. Berg, G. Heinemeyer, A. Lampen, Toxicology and risk assessment of 5-hydroxymethylfurfural in food, Mol. Nutr. Food Res. 55 (2011) 667-678.

[12] J.H.E. Arts, H. Muijser, M.J. Appel, C.F. Kuper, J.G.M. Bessems, R.A. Woutersen, Subacute (28-day) toxicity of furfural in Fischer 344 rats: a comparison of the oral and inhalation route, Food Chem. Toxicol. 42 (2004) 1389-1399.

[13] V.B. Godfrey, L.J. Chen, R.J. Griffin, E.H. Lebetkin, L.T. Burka, Distribution and metabolism of (5-hydroxymethyl) furfural in male F344 rats and B6C3F1 mice after oral administration, J. Toxicol. Environ. Health, Part A 57 (1999) 199-210.

[14] C. Janzowski, V. Glaab, E. Samimi, J. Schlatter, 5-Hydroxymethylfurfural: assessment of mutagenicity, DNA-damaging potential and reactivity towards cellular glutathione, Food Chem. Toxicol. 38 (2000) 801-809.

[15] G. Arribas-Lorenzo, F.J. Morales, Estimation of dietary intake of 5hydroxymethylfurfural and related substances from coffee to Spanish population, Food Chem. Toxicol. 48 (2010) 644-649.

[16] M. Castellari, E. Sartini, U. Spinabelli, C. Riponi, S. Galassi, Determination of carboxylic acids, carbohydrates, glycerol, ethanol, and 5-hmf in beer by high-performance liquid chromatography and UV-refractive index double detection, J. Chromatogr. Sci. 39 (2001) 235-238. 
[17] A. Alcázar, J.M. Jurado, F. Pablos, A.G. González, M.J. Martin, HPLC determination of 2-furaldehyde and 5-hydroxymethyl-2-furaldehyde in alcoholic beverages, Microchem. J. 82 (2006) 22-28.

[18] L.A. Ameur, G. Trystram, I. Birlouez-Aragon, Food chemistry accumulation of 5-hydroxymethyl-2-furfural in cookies during the backing process: validation of an extraction method, Food Chem. 98 (2006) 790-796.

[19] L. Basumallick, J. Rohrer, Determination of hydroxymethylfurfural in honey and biomass, Thermo Sci. Appl. (2013) 1-6.

[20] J.L. da Silva, M.A. Beluomini, N.R. Stradiotto, Determination of furanic aldehydes in sugarcane bagasse by high-performance liquid chromatography with pulsed amperometric detection using a modified electrode with nanoparticles, J. Sep. Sci. 38 (2015) 3176-3182

[21] F.C. Biluca, F.D. Betta, G.P. de Oliveira, L.M. Pereira, L.V. Gonzaga, A.C.O. Costa, R. Fett, 5-HMF and carbohydrates content in stingless bee honey by CE before and after thermal treatment, Food Chem. 159 (2014) 244-249.

[22] M.O.K. Franco, W.T. Suarez, V.B. dos Santos, Digital image method smartphonebased for furfural determination in sugarcane spirits, Food Anal. Methods 10 (2016) 508-515.

[23] P.T. Anastas, M.M. Kirchhoff, Origins, current status, and future challenges of green chemistry, Acc. Chem. Res. 35 (2002) 686-694.

[24] N.C. Dias, M.D. Porter, J.S. Fritz, Principles and applications of colorimetric solidphase extraction with negligible depletion, Anal. Chim. Acta 558 (2006) 230-236.

[25] M. Tubino, A.V. Rossi, M.E.A. de Magalhães, Quantitative spot tests of $\mathrm{Fe}(\mathrm{III}), \mathrm{Cr}(\mathrm{VI})$ and $\mathrm{Ni}(\mathrm{II})$ by reflectance measurements, Anal. Lett. 30 (1997) 271-282.

[26] V.H.M. Luiz, L. Pezza, H.R. Pezza, Rapid determination of furosemide by combined spot test/diffuse reflectance spectroscopy to detect doping in sport, Microchem. J. 109 (2013) 68-72.

[27] E.L. Rossini, M.I. Milani, L. Pezza, H.R. Pezza, A new eco-friendly methodology for the determination of Amaranth dye in foodstuffs using diffuse reflectance spectroscopy, Anal. Methods 8 (2016) 4086-4092.
[28] E. Carrilho, A.W. Martinez, G.M. Whitesides, Understanding wax printing: a simple micropatterning process for paper-based microfluidics, Anal. Chem. 81 (2009) 7091-7095.

[29] H. Yagoda, Applications of confined spot tests in analytical chemistry, Ind. Eng. Chem. 9 (1937) 79-82.

[30] J. Adkins, K. Boehle, C. Henry, Electrochemical paper-based microfluidic, Electrophoresis 36 (2015) 1811-1824.

[31] D.M. Cate, J.A. Adkins, J. Mettakoonpitak, C.S. Henry, Recent developments in paperbased microfluidic devices, Anal. Chem. 87 (2015) 19-41.

[32] W. Dungchai, O. Chailapakul, C.S. Henry, Use of multiple colorimetric indicators for paper-based microfluidic devices, Anal. Chim. Acta 674 (2010) 227-233.

[33] K. Castoldi, M.I. Milani, E.L. Rossini, L. Pezza, H.R. Pezza, Flow injection analysis of 5(hydroxymethyl)-2-furaldehyde in honey by a modified Winkler method, Anal. Sci. 32 (2016) 413-417.

[34] O. Winkler, Beitrag zum nachweis und zur bestimmung von oxymethylfurfurol in honig und kunsthonig, Zeitschrift Für Leb. Und-Forsch. 102 (1955) 161-167.

[35] A. Ghauch, C. Turnar, C. Fachinger, J. Rima, A. Charef, J. Suptil, M. Martin-Bouyer, Use of diffuse reflectance spectrometry in spot test reactions for quantitative determination of cations in water, Chemosphere 40 (2000) 1327-1333.

[36] I. Taverniers, M. De Loose, E. Van Bockstaele, Trends in quality in the analytical laboratory II. Analytical method validation and quality assurance, Trends Anal. Chem. 23 (2004) 535-552.

[37] L. Huber, Validation of analytical methods: review and strategy, LC/GC Mag. 21 (1999) 1-17.

[38] M. Thompson, S.L.R. Ellison, R. Wood, Harmonized guidelines for single-laboratory validation of methods of analysis, Pure Appl. Chem. 74 (2002) 835-855. 